\title{
Always take a travel history in eosinophilia
}

\author{
Nick J Beeching senior lecturer (clinical) in infectious diseases ${ }^{1}$, Imelda Bates reader in tropical \\ haematology ${ }^{2}$
}

${ }^{1}$ Clinical Group, Liverpool School of Tropical Medicine, Liverpool L3 5QA, UK; ${ }^{2}$ Disease Control Strategy Group, Liverpool School of Tropical Medicine

We emphasise the need to take a travel history from all patients with eosinophilia and to clarify the appropriate investigations for parasitic infections, the most common cause of eosinophilia worldwide. ${ }^{1}$ Delay in taking a travel history can have serious consequences, such as failure to diagnose and treat asymptomatic strongyloidiasis before immunosuppressive therapy is given. ${ }^{2}$ However, travel histories are obtained from less than $20 \%$ of British adults with acute clinical syndromes that might be travel related. ${ }^{3}$

Eosinophilia is typically caused by helminths, not giardiasis or most other protozoal infections. Examination of the famous "hot stool" for ova, cysts, and parasites is only needed when amoebic dysentery is suspected, in which case faeces, mucus, or rectal scrapings should be examined immediately for motile trophozoites of Entamoeba histolytica with ingested erythrocytes. Amoebiasis is not usually associated with eosinophilia, although this is a common misconception. ${ }^{4}$

For other parasites, the examination of fresh or preserved faecal specimens is not quite so urgent, and the choice of other investigations, including serological screening, depends on many factors. Strongyloidiasis is ubiquitous in the tropics, but eosinophilia in travellers or immigrants from Africa is more likely to be caused by schistosomiasis or loiasis. Comprehensive British guidelines on the diagnosis and management of travel related eosinophilia have recently been published. ${ }^{5}$

We recommend the automatic generation of reminders in laboratory reports on full blood counts with raised eosinophils, along the lines of, "Note the presence of eosinophilia. Have you taken a travel and drug exposure history?" These could be added to the learning points tabled by Sims and Erber. ${ }^{1}$

Competing interests: None declared.

Sims $\mathrm{H}$, Erber WN. Investigation of an incidental finding of eosinophilia. BMJ 2011;342:d2670. (18 May.)

2 Marcos LA, Terashima A, Canales M, Gotuzzo E. Update on strongyloidiasis in the immunocompromised host. Curr Infect Dis Rep 2011;13:35-46.

Price VA, Smith RAS, Douthwaite S, Thomas S, Almond DS, Miller ARO, et al. General physicians do not take adequate travel histories. J Trav Med (forthcoming).

physicians do not take adequate travel histories. J Trav Med (forthcoming).
Douglas C. The greatest breakthrough since lunchtime. Canongate Press, 1977.

5 Checkley AM, Chiodini PL, Dockrell DH, Bates I, Thwaites GE, Booth HL, et al. Eosinophilia in returning travellers and migrants from the tropics: UK recommendations for investigation and initial management. $J$ Infect 2010;60:1-20.

Cite this as: $B M J 2011 ; 342: \mathrm{d} 3688$ 